\title{
Concerning women: questionnaire survey of consultations, embarrassment, and views on confidentiality in general practice among women in their teens, thirties and fifties
}

\author{
Clare Seamark, Sue Blake
}

\begin{abstract}
Background Concern exists that women, and in particular teenagers, do not consult in general practice, particularly for contraception because of embarrassment and concern over confidentiality. The aim of this study was to compare reported consultation rates, embarrassment when consulting, and views on confidentiality of women in three age groups.
\end{abstract}

Methods A postal questionnaire was used to survey women aged 16-19, 36-39 and 56-59 years attending a semi-rural practice in East Devon, UK in December 1999.

Results Response rates of $57 \%$ (teenagers), $79 \%$ (women in their thirties) and $89 \%$ (women in their fifties) were achieved. In each group over half the respondents had seen a general practitioner (GP) in the previous 3 months. Embarrassment at attending a GP decreased from $38 \%$ of teenagers to only $16 \%$ of women in their fifties. There was a similar pattern with $78 \%$ of teens and $42 \%$ of women in their fifties preferring to see a woman doctor for a women's problem and $31 \%$ of teens and $18 \%$ of women in their fifties expressing a preference for a woman doctor for any problem. Some $97 \%$ of women in their thirties and fifties thought a consultation with a GP would be confidential compared with $88 \%$ of the teenagers. Only $9 \%$ of the teenage group thought the GP might tell their parents about the consultation.

Conclusions This study found that teenagers were just as likely as older women to have seen a GP in the preceding 3 months. Embarrassment at attending decreased with age, as did the preference to see a female doctor for both women's and any problems. The majority of women in each age group believed a consultation with a GP, or practice nurse, was confidential.

J Fam Plann Reprod Health Care 2005; 31(1): 31-33 (Accepted 4 November 2004)

\section{Key message points}

- Contrary to some expectations, teenagers are as likely as older women to consult their general practitioner (GP).

- In the older women, embarrassment at consulting and preference for a female doctor decreased. In general, even when women are embarrassed, it does not usually stop them consulting their GP.

- The vast majority of women of all ages believe consultations in general practice are confidential. Very few female teenagers think their parents will be informed about a consultation.

The Honiton Group Practice, Honiton, UK Clare Seamark, MD, MFFP, General Practitioner Sue Blake, BSc, Research Assistant

Correspondence to: Dr Clare Seamark, The Honiton Group Practice, Marlpits Lane, Honiton, Devon EX14 2NY, UK.

E-mail: cjseamark@doctors.org.uk

\section{Introduction}

Women's attitudes on attending their general practitioner (GP) are important as they may influence both the uptake of screening and contraceptive services and also attendance with potentially serious symptoms. This may be particularly important for teenagers who, it has been suggested, do not consult their GP because of concerns about confidentiality, ${ }^{1-8}$ and because they believe a parent may be informed of their visit. ${ }^{3}$ Teenagers are often seen as a healthy group with few major illnesses who do not need much medical attention and, indeed, consultations with adolescents can be shorter than average. ${ }^{9-13}$ Embarrassment when attending a general practice has also been cited as a reason for non-attendance by teenagers. ${ }^{1,14,15}$ This has not previously been compared with embarrassment felt by older women. The gender of the GP and possibly their age may also be important with regard to attendance for contraception, and possibly lower rates of teenage pregnancy. ${ }^{16,17}$ The attitude and understanding of GPs regarding confidentiality are also important. ${ }^{12,18,19}$

The Honiton Group Practice has tried to ensure that teenagers are able to consult GPs with few obstacles. A previous study in the Honiton practice has shown that the majority of women aged 16-19 years had consulted for contraceptive advice. ${ }^{20}$

The present study was designed to examine the pattern of consultations by women in the three very different age groups from teens to fifties. It also sought to discover the level of embarrassment felt among teenagers consulting their GP for a variety of conditions and also to compare this with women in the older age groups. This was part of a more extensive study looking at the experiences of women at different ages. ${ }^{21}$ The women were also asked their views on confidentiality when consulting both a GP and a practice nurse.

\section{Methods}

The study was set in Honiton, a semi-rural market town serving a population of about 15000 people at the time of the study. Honiton is very much in the middle of England in terms of deprivation indices with Townsend scores of -0.8 and 1.48 for the two town wards. At the time the study was conducted, there were six full-time male partners and five part-time partners of whom four were female, and a female retained doctor. There are no immediately available alternative providers of family planning services. The nearest accessible clinic is in Exeter some 16 miles away, although some women may access this clinic if they are working or attending college in the city. Likewise, the nearest genitourinary medicine clinic is also in Exeter and has limited appointment times. The local community hospitals (medical cover provided by GPs) provide free emergency contraception (EC) and many of the pharmacists offer EC, although this service usually attracts a fee.

The practice has been a research practice since 1995 The practice records are extensively computerised using the Exeter System. Women aged 16-19, 36-39 and 56-59 years on 1 December 1999 formed the study population. 


\section{ARTICLE}

The study received approval from the local medical research ethics committee.

Postal questionnaires were sent to individuals in the teenage $(n=281)$, thirties $(n=406)$ and fifties $(n=331)$ age groups in December 1999 together with a reply-paid envelope for return of the questionnaire. Nonrespondents were sent a second questionnaire in February 2000 but no further attempt to improve the response rate was made.

The questionnaire asked the same questions of women in all age groups concerning attendance at the practice, embarrassment when consulting, preference for a female doctor and views on confidentiality. Further questions specific to the age of the respondent were included and these are reported separately.21 The returned questionnaires were analysed using the Chi-square test. The results were compared with practice-held data.

\section{Results}

Completed questionnaires were returned by $160 / 281$ $(57 \%)$ in the teen group, $319 / 406(79 \%)$ in the thirties group and 294/331 (89\%) in the fifties group. Of these, 105 [66\%, confidence interval (CI) 59-73\%] teenagers reported having seen a GP in the previous 3 months compared with $166(52 \%$, CI $47-58 \%)$ women in their thirties and 173 (59\%, CI 53-65\%) women in their fifties. There was no significant difference in attendances between those in their teens and fifties and those in their thirties and fifties, but the teenagers were more likely to have attended than those in the thirties group $\left(\chi^{2}=8.01, p<0.01\right)$.

As the response rate from the teenagers was the lowest, the records of the non-respondents were searched for their attendance with a GP in the previous 3 months. In this group of non-respondents, 73/121 (60\%) had also attended (overall attendance for the teenage group was $178 / 281$, i.e. $63 \%$ ).

When asked about general embarrassment on attending their GP, 60/160 (38\%, CI 31-46\%) teenagers reported embarrassment compared with $74 / 312(23 \%, \mathrm{CI}$ $18-28 \%)$ women in their thirties and $46 / 294(16 \%, \mathrm{CI}$ $12-20 \%)$ women in their fifties. The teenagers were significantly more likely to report overall embarrassment compared with the women in their thirties $\left(\chi^{2}=9.88\right.$, $p<0.01)$ and even more so compared with the women in their fifties $\left(\chi^{2}=27.65, p<0.001\right)$. Women in their thirties were significantly more embarrassed than women in their fifties $\left(\chi^{2}=6.21, p<0.02\right)$, although the confidence limits overlap.

The women were asked about embarrassment when attending for specific conditions (Table 1). The most embarrassing condition for all women was vaginal

Table 1 Conditions that women find more or less embarrassing to discus. with their general practitioner ${ }^{a}$

\begin{tabular}{llll}
\hline Condition & \multicolumn{2}{l}{ Age group } & \\
\cline { 2 - 4 } & $\begin{array}{l}\text { Fifties } \\
(n=294)\end{array}$ & $\begin{array}{l}\text { Thirties } \\
(n=319)\end{array}$ & $\begin{array}{l}\text { Teens } \\
(n=160)\end{array}$ \\
\hline Vaginal discharge & 27 & 44 & 72 \\
Cervical smear & 18 & 32 & 61 \\
Breast lump & 10 & 28 & 50 \\
Relationship difficulties & 23 & 34 & 36 \\
Contraception & - & 10 & 36 \\
Sore throat & 3 & 3 & 3 \\
Travel advice & 3 & 1 & 3
\end{tabular}

aThe figures quoted in the table are the percentage of women indicating embarrassment with regard to each condition.

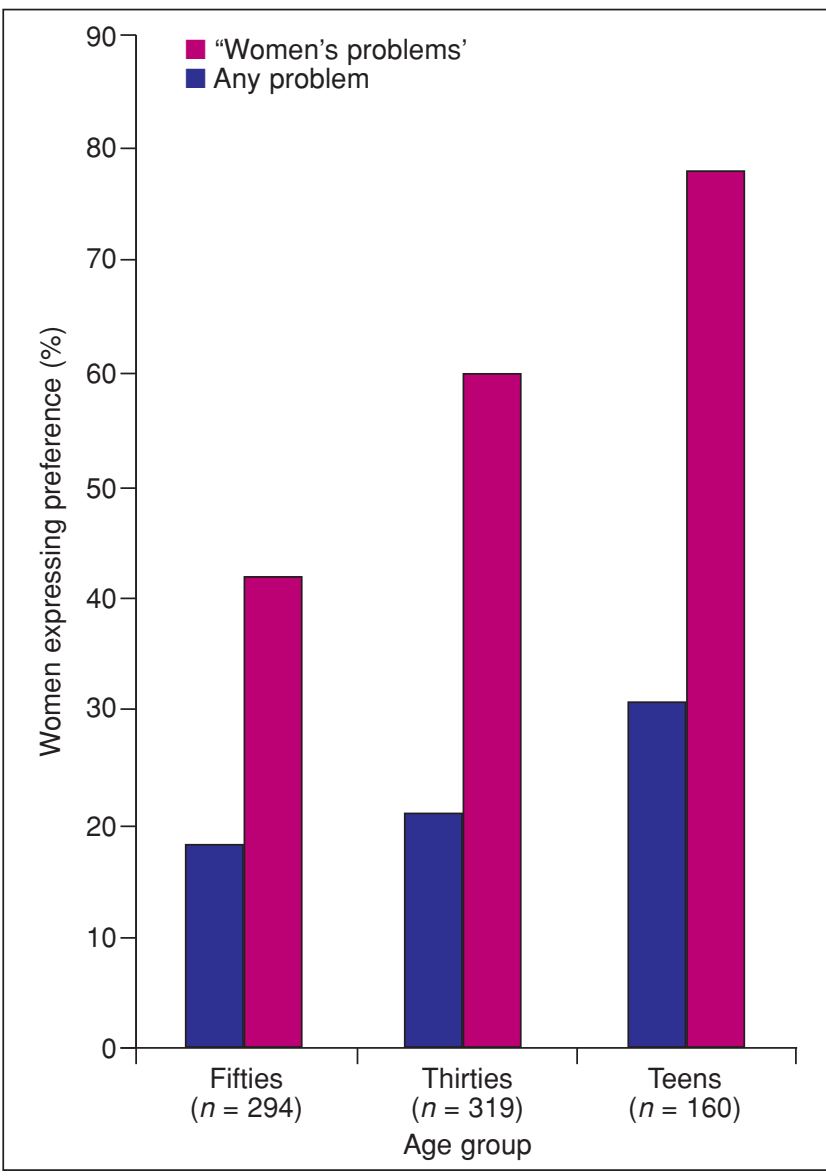

Figure 1 Women's preferences for a woman doctor depending on the type of problem about which they are consulting

discharge and the least embarrassing was travel advice. Overall, the women in their fifties had lower rates for embarrassment and the teenagers higher rates, particularly for cervical smears (the questionnaire informed the teenagers that they would not need a cervical smear until they were 20) and breast lumps.

Regarding the gender of the doctor, in all age groups the women showed greater preference for a female doctor when attending for 'women's problems' (Figure 1). In the fifties group, $123 / 294$ (42\%, CI 36-48\%) expressed a preference compared with $191 / 319$ in the thirties group $(60 \%$, CI 54-65\%) and 125/160 in the teen group (78\%, CI 72-84\%). Women in their fifties were significantly less likely to express this preference than women in their teens $\left(\chi^{2}=55.05, p<0.001\right)$ and women in their thirties $\left(\chi^{2}=19.92, p<0.001\right)$. Women in their thirties were less likely than the teenagers to prefer a woman doctor $\left(\chi^{2}=15.81, p<0.001\right)$. A preference to see a woman doctor for 'any problem' showed the same trend. There was no significant difference between women in their thirties and fifties, but the teenagers were more likely to prefer a woman doctor than the thirties group $\left(\chi^{2}=6.06, p<0.002\right)$ and the fifties group $\left(\chi^{2}=9.74, p<0.001\right)$.

Women in all the age groups were asked whether they had any concerns that what they said in a consultation with a GP or practice nurse would not be confidential/private. Of the teen group, $135 / 154$ (88\%, CI $83-92 \%)$ had no concerns about confidentiality with a GP (six individuals did not answer the question) and 129/155 (83\%) had no concerns about confidentiality with the practice nurse (five did not answer). For women in their thirties, only $9 / 316$ $3 \%)$ had concerns about confidentiality with the GP and $13 / 311$ (4\%) with the practice nurse. The same proportions 
were found in the fifties group, with 10/324 (3\%) women having concerns with the GP and 14/322 (4\%) with the practice nurse. The teenagers were asked whether they thought the GP would tell their parents about a private discussion. Five did not answer the question and one was not sure, but 141/155 (91\%) did not think the doctor would tell their parents.

\section{Discussion}

The strengths of this study come from a very satisfactory response to a postal questionnaire. Rates of $89 \%$ for the fifties group and $79 \%$ for the thirties group would be considered excellent, and a response rate of $57 \%$ for teenagers compares well with previous studies, ${ }^{3,5,22}$ It is reassuring that the consultation rates for contraception among respondents and non-respondents in the teenage group are comparable.

Although the data relate to only one practice, and one with a high rate of consultation among teenagers for contraception, the results may be applicable to practices with similar population characteristics and staffing.

Over half the respondents in each age group had attended a GP in the preceding 3 months and the rate was if anything higher for the teenagers. Others have found that only $30 \%$ of teenagers reported seeing a GP over this time span. ${ }^{23}$ A survey of attendance in general practice in Honiton and the neighbouring town of Ottery St Mary found that in 1 year $84 \%$ of females and $69 \%$ of males aged 13-19 years had attended the practices for a consultation. This figures is far in excess of the $53.5 \%$ reported for teenagers in a London practice. ${ }^{24}$

Some women of all ages responded that they felt embarrassed when consulting a GP and so it is likely that some degree of embarrassment is normal. The rate of embarrassment decreased with age, suggesting that women do get used to attending. Two-thirds of teenagers did not report embarrassment in relation to contraception, which is encouraging and consistent with data from Northern Ireland showing that more than $90 \%$ of 110 15-19-yearolds drawn from different practices felt they could discuss any problem with a GP. ${ }^{25}$ The vast majority of women in all three age groups had confidence in the privacy of their consultation with a GP or a practice nurse. Over $91 \%$ of the teenage group did not think that a doctor would tell their parents about the consultation. Previous studies have suggested higher concerns about confidentiality, with 58\% of 13-15-year-olds expressing concern in a school-based survey in London.?

\section{Conclusions}

This questionnaire survey achieved very high response rates from women in their thirties and fifties and an acceptable rate from the teenage group. Over half of each group had seen a GP in the preceding 3 months, with teenagers being more likely to have attended than women in their thirties. Embarrassment at attending decreased with age, as did preference for a female GP for both 'any problem' and a 'women's problem'. However, more than double the women in each age group preferred a woman GP for 'women's problems' than for 'any problem'. The vast majority of women in each age group believed that a consultation with a GP or a practice nurse was confidential. Of the teenagers, $91 \%$ did not believe that a GP would tell their parents about the consultation. This study would suggest high levels of attendance among these women, decreasing embarrassment and preference for a female doctor with age, and widespread confidence in the confidentiality of the consultation.
Acknowledgements

The authors wish to thank the partners and staff of the Honiton Group Practice and all the women who participated in this study.

\section{Statements on funding and competing interests}

Funding. The Honiton Group Practice is a National Health Service-funded research practice. Dr Clare Seamark held a RCGP/BUPA Research research practice. Dr Clare Seamark held a RCGP/BUPA Research
Fellowship from 1998 to 2000. Schering Health Care Ltd and Wyeth Laboratories gave grants to support this project.

Competing interests. None identified.

References

1 Hollander D. Some teenagers say they might not seek health care if they could not be assured of confidentiality. Fam Plann Perspect 1993; 25 : 187

2 Macfarlane A, McPherson A. Primary health care and adolescence. BMJ 1995; 311: 825-826.

3 Donovan C, Mellanby AR, Jacobson LD, Taylor B, Tripp JH. Teenagers' views on the general practice consultation and provision of contraception. The Adolescent Working Group. Br J Gen Pract of contraception. The

4 Kari J, Donovan C, Li J, Taylor B. Adolescents' attitudes to general practice in North London. Br J Gen Pract 1997; 47: 109-110.

5 Scally G. Confidentiality, contraception and young people. BMJ 1993; 307: 1157-1158.

6 Jones R, Finlay F, Simpson N, Kreitman T. How can adolescents' health needs and concerns best be met? Br J Gen Pract 1997; 47: 631-634.

7 Burack R. Young teenagers' attitudes towards general practitioners and their provision of sexual health care. Br J Gen Pract 2000; 50: $550-554$.

8 Jacobson LD, Owen PA. Study of teenage care in one general practice. Br J Gen Pract 1993; 43: 349.

9 Bewley BR, Higgs RH, Jones A. Adolescent patients in an Inner London general practice: their attitudes to illness and health care. J Roy Coll Gen Pract 1984; 34: 543-546.

10 Jacobson L, Kinnersley P. Teenagers in primary care - continuing the new direction. Br J Gen Pract 2000; 50: 947-948.

11 Jacobson LD, Wilkinson C, Owen PA. Is the potential of teenage consultations being missed? A study of consultation time in primary care. Fam Pract 1994; 11: 296-299.

12 Jacobson LD, Wilkinson CE. Review of teenage health: time for a new direction. Br J Gen Pract 1994; 44: 420-424

13 Cowap N. GPs need to be more proactive in providing health care to teenagers. BMJ 1996; 313: 941

14 Churchill R, Allen J, Denman S, Williams D, Fielding K, von Fragstein M. Do the attitudes and beliefs of young teenagers towards general practice influence actual consultation behaviour? $\mathrm{Br} \mathrm{J}$ Gen Pract 2000; 50: 953-957.

15 Pearson VA, Owen MR, Phillips DR, Gray DJ, Marshall MN Teenage pregnancy: a comparative study of teenagers choosing termination of pregnancy or antenatal care. J R Soc Med 1995; 88 : 384-388.

16 Phillips D, Brooks F. Women patients' preferences for female or male GPs. Fam Pract 1998; 15: 543-547.

17 Hippisley-Cox J, Allen J, Pringle M, Ebdon D, McPhearson M, Churchill $\mathrm{D}$, et al. Association between teenage pregnancy rates and the age and sex of general practitioners: cross sectional survey in Trent 1994-7. BMJ 2000; 320: 842-845.

18 Garside R, Ayres R, Owen MR, Pearson VH, Roizen J. General practitioners' attitudes to sexual activity in under-sixteens. $J R$ Soc Med 2000; 93: 563-564.

19 Jacobson L, Richardson G, Parry-Langdon N, Donovan C. How do teenagers and primary healthcare providers view each other? An overview of key themes. Br J Gen Pract 2001; 51: 811-816.

20 Seamark C, Gray DJP. Do teenagers consult general practitioners for contraceptive advice? Br J Fam Plann 1995; 21: 50-51.

21 Seamark C, Blake S. Questionnaire survey of women aged 56-59 years: consultations in general practice, use of hormone replacement therapy (HRT) and participation in screening programmes. J Fam Plann Reprod Health Care 2002; 28: 15-17.

22 Jacobson LD, Mellanby AR, Donovan C, Taylor B, Tripp JH. Teenagers' views on general practice consultations and other medical advice. The Adolescent Working Group, RCGP. Fam Pract 2000; 17: advice. The 158 .

23 McPherson A, Macfarlane A, Allen J. What do young people want from their GP? Br J Gen Pract 1996; 46: 627.

24 Kramer T, Iliffe S, Murray E, Waterman S. Which adolescents attend the GP? Br J Gen Pract 1997; 47: 327.

25 Cupples M, Reilly P, Bradley T, Irvine H. GP opportunities for teenage health promotion. Br J Gen Pract 2000; 50: 581.

26 Milne AC, Chesson R. Health services can be cool: partnership with adolescents in primary care. Fam Pract 2000; 17: 305-308. 